
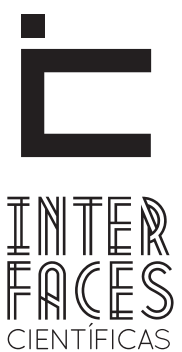

SAÚDE E AMBIENTE

\title{
CÂNCER DE PÊNIS: SOB A ÓTICA DA REPRESENTAÇ̃̃O SOCIAL DE PACIENTES SUBMETIDOS À AMPUTAÇ̃̃o DE PÊNIS E SUAS IMPLICAÇ̃̃ES PARA O CUIDADO DE SI
}

\author{
Silvio Eder Dias da Silva ${ }^{1}$ \\ Esleane Vilela Vasconcelos ${ }^{3}$ \\ Poliana dos Santos Alves ${ }^{5}$ \\ Gilmaira Pires Filgueira?
}

\author{
Érika de Cássia Lima Xavier ${ }^{2}$ \\ Jeferson Santos do Araújo ${ }^{4}$ \\ Natacha Mariana Farias da Cunha ${ }^{6}$
}

\section{RESUMO}

Objetivou-se identificar as representações sociais do câncer de pênis em pacientes penectomizados e suas implicações para o cuidado de si. A pesquisa é exploratória do tipo estudo de caso, com abordagem qualitativa, empregando-se a Teoria das Representações Sociais. Foram entrevistados 15 pacientes submetidos à penectomia, sendo feita a análise pelo método análise de conteúdo. Emergiram duas unidades temáticas: o significado do pênis após am-

putação de pênis e a representação do cuidado de si pós-penectomia. Apreendeu-se a necessidade de trabalhar focado no processo de enfermagem em todos os estágio da internação deste paciente, visando melhorar a sua autoaceitação.

\section{PALAVRAS-CHAVE}

Enfermagem. Câncer. Pênis. Amputação. 


\section{ABSTRACT}

This study aimed to identify the social representations of penis cancer in penectomized patients and its implications for self-care. The research is exploratory case study with a qualitative approach employing the Theory of Social Representations. 15 patients undergoing penectomy were interviewed, the analysis by using content analysis being done. Emerged two thematic units: the meaning of the penis after amputation and

\section{RESUMEN}

El objetivo fue identificar las representaciones sociales del cáncer de pene en pacientes penectomizados y sus implicaciones en lo que cabe al cuidado personal. La investigación exploratoria es caso de estudio con un enfoque cualitativo haciéndose uso de la Teoría de las Representaciones. Se entrevistó a 15 pacientes que se sometieron a penectomía, siendo realizado análisis por el método de análisis de contenido. Surgieron dos unidades temáticas: el significado del the representation of self-care post-penectomy. Seized the need to work focused on the nursing process throughout the stages of this patient's hospitalization to improve your self-acceptance.

\section{KEYWORD}

Nursing. Cancer. Penis. Amputation.

pene después de la amputación del pene, y la representación de los auto-cuidados post-penectomía. Se comprendió la necesidad de trabajar con enfoque al proceso de enfermería en cada etapa de la admisión de este paciente visando su auto-aceptación.

\section{PALAVRAS CLAVE}

Enfermería. Cáncer. Pene. Amputación. 


\section{INTRODUÇ̃̃O}

0 câncer de pênis é uma neoplasia rara, que atinge aproximadamente $1 / 100.000$ homens nos países desenvolvidos, sendo possível identificar sua alta incidência em países em desenvolvimento, incluindo o Brasil, onde é mais elevada nas regiões Norte e Nordeste, acometendo principalmente homens na terceira idade, independentemente de sua origem étnica, a doença acomete indivíduos de baixo nível social, com maus hábitos de higiene e não circuncisados, tendo como principal fator de risco a fimose, e muitas vezes esta associada ao papilomavírus humano -HPV (REIS, 2010).

No Pará, em 2009 e o primeiro semestre de 2010, foram cerca de 38 cirurgias de amputação de pênis, e está em $5^{\circ}$ lugar entres os estados que mais realizam este tipo de cirurgia no Brasil. 0 tratamento para a lesão primária é a amputação parcial ou total do pênis, dependendo do nível de acometimento deste. Em grande parte dos casos opta-se pela cirurgia para controle local da patologia, o diagnóstico precoce pode evitar a amputação do membro que produz sequelas físicas, sexuais e psicológicas no indivíduo (SOCIEDADE BRASILEIRA DE UROLOGIA, 2010).

Desde a infância, o pênis já representa o órgão de diferenciação entre os sexos, associando-se a essa ideologia temos a cultura pertinente a cada sociedade, que faz do homem um ser forte, viril, invulnerável, onde até mesmo $\mathrm{o}$ ato de chorar por dor ou medo é recriminado. Esse tabu imposto pela sociedade reflete muitas vezes na procura do serviço de saúde, fazendo com que o homem demore a procurar assistência, e consequentemente à detecção de doenças seja feita em estágio avançando, em se tratando do Câncer quanto mais cedo for feito o diagnóstico maior a perspectiva de um tratamento conservador.

Nesse sentido, a compreensão da representação social do paciente penectomizado, identifica os problemas psicossociais que irão interferir na adaptação de sua vida sexual, familiar e social, os quais poderão ser identificados pelo enfermeiro e trabalhados pela equipe multiprofissional para melhorar a percepção deste paciente, diante da sua realidade.

\section{OBJETIVO}

Identificar as representações sociais de homens com câncer de pênis sobre a amputação de pênis e suas implicações para o cuidado de si.

\section{MÉTODO}

Trata-se de uma pesquisa de abordagem qualitativa com emprego do método de estudo de caso. Adotando um suporte teórico-conceitual as representações sociais criadas por Serge Moscovici, estas são definidas como uma forma de conhecimento que os indivíduos passam a ter após vivenciarem uma determinada situação e a partir daí constroem suas práticas cotidianas, relacionando-as aos grupos a que pertencem (MOSCOVICl, 2003).

Os sujeitos foram 15 pacientes submetidos à penectomia total ou parcial em períodos diferentes de pós-operatório, procedimentos realizados em Hospital de Referência em Oncologia em Belém - Pará, consentindo seus depoimentos por meio do Termo de Consentimento Livre e Esclarecido. Quanto ao aspecto ético, o projeto foi submetido ao comitê de ética e pesquisa da Universidade Federal do Pará (UFPA), localizada em Belém do Pará, tendo sido aprovado pelo referido comitê, nº 026/11. 0 mesmo atendeu à Resolução no 196/96 do Conselho Nacional de Saúde. Para preservar o anonimato dos depoentes, empregamos o sistema alfanumérico para identificação dos relatos.

A coleta de dados foi realizada no período de maio a outubro de 2011, utilizando três técnicas de coleta: a livre associação de palavras, a entrevista semidirigida e a observação livre. Analisando os depoimentos foram 
construídas duas unidades temáticas, denominadas: o significado do pênis para os pacientes submetidos à amputação de pênis, e o de cuidado de si pós penectomia.

\section{RESULTADOS E DISCUSSÃO}

\subsection{SIGNIFICADO DO PÊNIS PARA OS PACIENTES SUBMETIDOS À AMPUTAÇÃO DE PÊNIS}

\subsubsection{Pênis: Órgão para Relação Sexual}

No processo de entrevistas os depoentes expressaram a importância do pênis para a manutenção da vida sexual, onde é possível evidenciar que homem é falocêntrico, ou seja, põe sua erotização no pênis e este consequentemente recebe os significados de procriação, virilidade, prazer e paternidade.

Na antiguidade, houve uma grande difusão sobre o Culto ao Falo (LACAN, 1998), sendo a ele atribuídos vários significados de acordo com o perfil da sociedade. É por meio da evolução da sociedade que é possível compreender a representatividade desse órgão para o homem, principalmente no que concerne a sexualidade (FREIDMAN, 2002). Essa significação cultural consiste das atitudes diárias adotadas pelos indivíduos, sendo que ela é constituída tanto de base material como pelas ideias, dentro de uma relação adequada, em que ambas se condicionam mutuamente. As ideias são juízos de valor que os indivíduos dotados de vontade possuem (WEBER, 1985).

As representações são um conjunto de conceitos, proposições e explicações originado na vida diária no curso das comunicações interindividuais. Elas são o equivalente, na nossa sociedade, dos mitos e sistemas de crenças das sociedades tradicionais; elas podem, também, ser vistas como a versão contemporânea do senso comum (MOSCOVICl, 1981).

\subsubsection{Pênis: Símbolo de Masculinidade}

Alguns depoentes ainda identificaram o pênis como órgão que define a masculinidade, a falta de seu órgão definidor põe em dúvida se ainda é homem, porém vale ressaltar que em nenhum momento eles sentem que agora são mulheres, mas na sua autopercepção são seres assexuados.

A perda do pênis para o homem significa a sua não adequação a natureza e sua condição cultural é responsável pela subversão de suas bases instituais, e o fazem regido pela pulsão, que não tem objeto determinado (FREUD, 1905).

A indeterminação da sexualidade no pós-cirúrgico é decorrente do modelo de perfeição que está representado na anatomia masculina, onde a regra fálica, distingue perfeitamente o domínio de superioridade e inferioridade masculina e feminina respectivamente. Com a perda do órgão sexual o homem passa a ter a ideia concebida como um homem inferior. Com o modelo de perfeição do corpo do macho, todas as outras características dependerão dessa forma (LAQUEUR, 2001). Dessa forma podemos perceber a negação à doença quando aos primeiros sinais o paciente não procura atendimento médico, decorrente desta visão patriarcal o homem é visto como um ser onipotente e introspectivo, representando assim o papel que a sociedade exige.

\subsubsection{Pênis: Símbolo de Tristeza}

A tristeza foi um dos significados dado ao pênis por uma parte dos depoentes. Definiram este órgão como causador de grande sofrimento. 0 sentimento de tristeza permeia a vida desses pacientes, ocasionado não só pela dor física que é vivenciada antes da cirurgia, mas, também, pela amputação de pênis. Os sintomas depressivos no período de hospitalização se deve ao fato da ansiedade a respeito dos procedimentos que será feito e ainda ao desconhecimento em relação ao futuro.

A representação mental do corpo é necessária no decorrer normal da vida, porém quando essa representação é prejudicada por meio de lesões cerebral ou traumas e ainda pela perda ou ausência 
de um segmento corporal, quando provocado uma brusca alteração da imagem corporal, esse impacto contribui para o aumento dos níveis de ansiedade, fazendo com que o paciente tenha uma visão distorcida e negativa sobre sua aparência (FITZPATRICK, 1999).

Não só as nossas imagens do mundo social são reflexo dos eventos do mundo social, mais os próprios do mundo social podem ser reflexos e produtos de nossas imagens do mundo social. Os preconceitos são dificilmente dissipados, os estereótipos não são enfraquecidos, pois, para Moscovici (2003), não existe nada na representação que não esteja na realidade, exceto a representação de si.

\section{A REPRESENTACC̄O SOCIAL DOS PACIENTES PENECTOMIZADOS SOBRE O CUIDADO DE SI}

\subsection{Descuidado com Pênis}

Os sinais de descuidado com o pênis surgem desde o primeiro momento, quando o homem percebe que houve o surgimento da lesão, porém os pacientes subestimam a doença e somente quando começam a sentir dor e a limitar suas atividades é que procuram assistência médica. 0 descuidado ou o dês-zelo com a saúde aflora quando o individuo nega a própria essência de ser-cuidado, tornando-se cruel consigo mesmo, tendo como resultado o processo de saúde e doença alterado, e consequentemente alterando o seu bem estar e sua qualidade de vida. Por conseguinte, descuido é definido como toda ação não valorativa empregada a algo ou alguém, neste caso, a saúde (BOFF, 2003).

A imagem do homem é construída a partir de seus comportamentos e crenças, que fazem com que o homem desde a infância tenha a obrigatoriedade de ser forte, tendo sempre o controle físico e emocional, com isso sua saúde e tratada de forma secundária, renunciando os cuidados ao seu próprio corpo (COURTENAY, 2000).
No caso do Câncer de Pênis uma de suas principais causas é a falta de higienização intima. Esta cultura está ligada a comportamento e crenças relacionados à saúde, à negação da fraqueza e vulnerabilidade, à aparência de ser forte e robusto, ao controle físico e emocional, à negação da necessidade de ajuda e à demonstração de comportamentos agressivos. A vulnerabilidade é construída considerando o individuo-coletivo e, portanto, envolve componentes individuais, sociais e pragmáticos. 0 componente individual relaciona-se com os valores pessoais e recursos preventivos, considerando o acesso à saúde e amparo social conforme condições de ordem cognitiva e comportamental. 0 componente social interliga os planos individuais aos sociais e consideram o acesso à informação ou ao desenvolvimento social (AYRES, 2007).

A subjetividade humana é definida como uma atitude que reporta a sentimentos, emoções e posicionamento, possuindo uma carga afetiva relevante na formação da representação, pois é por meio desta subjetividade que o sujeito imprime a sua marca pessoal na representação e exprime seu poder de criar e transformar sua realidade (MOSCOVICI, 1978).

A representação social é sempre a representação de alguma coisa e de um sujeito social. As características do sujeito e do objeto nela se manifestam, ou seja, o paciente pencetomizado a partir de suas vivências, tem condições suficientes para trazer as representações das falhas do cuidado de si que percebeu em sua vida, configurando nessas representações, sentimentos, ações e a realidade social do seu cotidiano (JODELET, 2001).

\subsection{Cuidado de Si Pós-Penectomia}

Os depoentes apresentaram a necessidade do cuidado de si após a cirurgia, enfatizando que a partir desse momento irão se resguardar para que seja restabelecido o mais rápido possível seu estado de saúde e fortalecem a ideia de que a qualquer alteração na região genital irão procurar atendimento médico o mais breve possível. 
Por meio dos conteúdos expressos nas informações, imagens, opiniões, atitudes e outros é que se relacionam com o ser objeto de cuidado, cria-se uma representação social, ou seja, um trabalho a realizar, um acontecimento econômico, um personagem social; converge, também, a representação social de um sujeito, de um grupo, em relação a outro sujeito, pois as representações sociais são definidas a partir de conteúdos expressos do seu dia a dia, que lhes motivem comportamentos, saberes e atitudes (RADÜNZ, 2001).

Com o passar dos anos, o homem desenvolve seu potencial pelo cuidado, sendo este construído conforme sua cultura, sua crenças, os valores e as vivências advindos do contexto ambiental em que cada ser esta inserido, defendendo dessa forma sua sobrevivência.

Um depoente expressou em seu relato que mesmo após serem repassadas todas as informações sobre as possíveis causas para o aparecimento da doença, ele manifestou um comportamento de cuidado exacerbado. No passado, falta de conhecimento em relação ao Câncer levava à associação com doenças venéreas, apesar de passado muitos anos após a descoberta dos fatores causais do Câncer, ainda temos à cultura arraigada a concepção de esta patologia ser em uma doença contagiosa, principalmente em pacientes com baixo grau de escolaridade e de procedência interiorana.

0 cuidado de si pode ser trabalhado por todos os profissionais da área da saúde, porém há necessidade de sensibilização desta categoria para a disseminação da promoção da saúde, dessa forma será possível melhorar a qualidade de vida dos pacientes penectomizados, que após a cirurgia necessitarão de vigilância constante para possível recidiva da doença e ainda a prevenção que deveria ser fortemente trabalhada.

\section{CONCLUSÃO}

Este estudo evidenciou as representações sociais do câncer de pênis em pacientes submetidos à amputação de pênis e implicações para o cuidado de si. Ao realizarmos a pesquisa, percebemos a importância de conhecer o significado desta nova condição que o paciente se apresenta, devido ser um momento de intensas transformações sociais e psicológicas, visto que a percepção de si assumirá uma nova forma a qual dependerá de como ele se identificará após a penectomia.

A relevância da Enfermagem neste processo relaciona-se a identificar por meio do processo de enfermagem ações que reduzam este impacto ao paciente. A busca pelo olhar holístico do enfermeiro sobre o paciente emerge a necessidade de conhecer as representações sociais, visando melhorar a assistência prestada ao homem não só nos hospitais quando estes estão com a saúde debilitada, mas também nas unidades básicas de saúde, podendo ser alertado o problema aos homens e por que não, também, para as mulheres, já que elas poderão divulgar as informações em seus lares.

\section{REFERÊNCIAS}

AYRES, JRCM. Uma concepção hermenêutica de saúde. Physis, 17(1), 43-62. 2007.

BOFF, L. Saber cuidar: ética do humano-compaixão pela terra. 9.ed. Petropólis: Vozes, 2003.

COURTENAY, WH. Constructions of masculinity and their influence on men's well-being: theory of gender and health. Soc Sci Med; 50:1385-401, 2000.

FITZPATRICK, M. The psychologic assessment and psychossocial recovery of the patient with an amputation. Clinical orthopaedics and related research, 361, 98-107, 1999 
FREIDMAN, DM. Uma mente própria: A história cultural do pênis. Rio de Janeiro: Objetiva, 2002.

FREUD, S. Três Ensaios Sobre a Teoria da Sexualidade. Rio de Janeiro: Imago, Standart Brasileira, Obras Completas, v.VII, p.117-231, 1905

JODELET, D. Representação Social: um domínio em expansão. Rio de Janeiro: UERJ, 2001.

LACAN, J. Significação do falo, A [1958]. In: Escritos. Rio de Janeiro: Jorge Zahar, 1998.

LAQUEUR, TW. Inventando o sexo: corpo e gênero dos gregos a Freud. Rio de Janeiro: Relume Dumará, 2001.

MOSCOVICI, S. A Representação Social da Psicanálise. Rio de Janeiro: Zahar, 1978.

MOSCOVICI, S. On social representations. In: FORGAS, JP. (Ed). Social cognition: perspective on everyday understanding. London: Academic Press, 1981.
MOSCOVICl, S. Investigações em psicologia social. 2.ed. Petrópolis: Vozes, 2003.

RADÜNZ, V. Uma filosofia para enfermeiros: o cuidado de si, a convivência com a finitude e a evitabilidade do burnout. Florianópolis: PEN/UFSC: 2001.

REIS, AAS et al. Aspectos clínicos-epidemiológicos associados ao Câncer de Pênis. Ciência \& Saúde Coletiva, v.15 (supl.1), p.1105-1111, Rio de Janeiro, Jun. 2010.

SOCIEDADE BRASILEIRA DE UROLOGIA. Câncer de pênis. 2010. Disponível em: <http://www.sbu.org. $\mathrm{br} /$ ?s $=\mathrm{C} \% \mathrm{C} 3 \% 82 \mathrm{NCER}+\mathrm{DE}+\mathrm{P} \% \mathrm{C} 3 \% 8 \mathrm{ANIS} \& \mathrm{x}=32$ \&y=14>. Acesso em: 1 out. 2010.

WEBER, M. A ética protestante e o espírito do capitalismo. São Paulo: Pioneira, 1985. 
1. Orientador e professor da Universidade Federal do Pará. Doutor em Enfermagem pelo DINTER UFPA/UFSC Belém (PA) Brasil. E-mail: silvioeder@ ufpa.br Telefone: (91) 81580748.

2. Discente de graduação em Enfermagem da Universidade Federal do Pará. Belém (PA) Brasil. E-mail: erikaxavier@yahoo.com.br

3. Professora da Universidade Federal do Pará. Mestre em Enfermagem pela Universidade do Estado do Pará. Belém (PA) Brasil. E-mail: leanevas@hotmail.com

4. Doutorando do Doutorado da USP/RP. E-mail: jeferson-ma@ig.com.br

5. Discente de graduação em Enfermagem da Universidade Federal do Pará - Bolsista PIBIC/CNPq. Membro do Grupo de Pesquisa Educação, Políticas e Tecnologia em Enfermagem da Amazônia (EPOTENA). Belém (PA) Brasil. E-mail: polianaalves_@hotmail.com

6. Discente de graduação em Enfermagem da Universidade Federal do Pará - Bolsista PIBIC/CNPq. Membro do Grupo de Pesquisa Educação, Políticas e Tecnologia em Enfermagem da Amazônia (EPOTENA). Belém (PA) Brasil. 